\title{
FORMATION OF WATER ON SILICATE SURFACES UNDER INTERSTELLAR CONDITIONS
}

\author{
H. Chaabouni ${ }^{1}$, M. Minissale ${ }^{1}$, F. Dulieu ${ }^{1}$, E. Congiu ${ }^{1}$, M. Accolla ${ }^{2}$, \\ S. Baouche ${ }^{1}$ and J.-L. Lemaire ${ }^{1}$
}

\begin{abstract}
We explore experimentally the formation of water molecules from $\mathrm{O}_{2}$ and $\mathrm{D}$ atoms on bare grains composed of amorphous silicates analogous to those in diffuse interstellar clouds. We provide the fractions of $\mathrm{D}_{2} \mathrm{O}$ and $\mathrm{D}_{2} \mathrm{O}_{2}$ molecules formed on the silicate surface held at $10 \mathrm{~K}$ from the $\mathrm{O}_{2}+\mathrm{D}$ pathway using RAIRS and TPD techniques. For comparison, we also study the formation of water molecules on surfaces covered with amorphous water ice representing the dense clouds.
\end{abstract}

Solid water ice is a very abundant astrophysical material. It is believed to be the most abundant condensed component in the universe and particularly in dense molecular clouds. It is also the most abundant species in icy mantles. Water ice is likely to form directly on the surface of dust grains through $\mathrm{H}$ atom addition reactions. Three different hydrogenation channels have been proposed for water formation (Tielens \& Hagen 1982) where dust grains play a role of catalyst: $\mathrm{O}+\mathrm{H}$ (Dulieu et al. 2010; Jing et al. 2011), $\mathrm{O}_{2}+\mathrm{H}$ (Miyauchi et al. 2008; Ioppolo et al. 2008) and $\mathrm{O}_{3}+\mathrm{H}$ (Mokrane et al. 2009).

The process of water formation from $\mathrm{O}_{2}+\mathrm{H}$ and $\mathrm{O}_{2}+\mathrm{D}$ pathways follows these reactions:

$$
\begin{gathered}
\mathrm{D}+\mathrm{O}_{2} \longrightarrow \mathrm{DO}_{2} \\
\mathrm{D}+\mathrm{DO}_{2} \longrightarrow \mathrm{D}_{2} \mathrm{O}_{2}, \\
\mathrm{D}+\mathrm{D}_{2} \mathrm{O}_{2} \longrightarrow \mathrm{D}_{2} \mathrm{O}+\mathrm{OD} \\
\mathrm{D}+\mathrm{OD} \longrightarrow \mathrm{D}_{2} \mathrm{O}
\end{gathered}
$$

1 LERMA, UMR 8112 du CNRS, Observatoire de Paris et Université de Cergy Pontoise, 5 mail Gay Lussac, 95000 Cergy Pontoise Cedex, France; e-mail: Henda.Chaabouni@obspm.fr

2 Dipartimento di Scienze Applicate - Università Parthenope di Napoli Centro Direzionale, Isola C4, 80143 Napoli, Italy 
Our experiments were performed using the FORMOLISM (FORmation of MOLecules in the ISM) setup, which consists of an ultra-high vacuum (UHV) stainless steel chamber with a base pressure lower than $1 \times 10^{-10}$ mbar.

In the experiments a silicate sample held at $10 \mathrm{~K}$ is exposed to $\mathrm{O}_{2}$ molecules, and the oxygen ice film $(\sim 1 \mathrm{ML})$ is irradiated with $\mathrm{D}$ atoms for several exposure times at the same surface temperature. Both RAIRS and TPD results showed the formation of $\mathrm{D}_{2} \mathrm{O}$ and $\mathrm{D}_{2} \mathrm{O}_{2}$ molecules as well as $\mathrm{D}_{2}$ molecules. The fraction of $\mathrm{D}_{2} \mathrm{O}$ molecules formed on the cold silicate sample when all the $\mathrm{O}_{2}$ molecules leave the surface is about $(18 \%)$ and that of $\mathrm{D}_{2} \mathrm{O}_{2}$ molecules is $(\sim 23 \%)$.

It is probable that most of the $\mathrm{D}_{2} \mathrm{O}$ molecules formed on the surface desorb into the gas phase upon formation. Their fraction is $(\sim 82 \%)$ of the total $\mathrm{D}_{2} \mathrm{O}$ molecules expected to be formed from the $\mathrm{O}_{2}+\mathrm{D}$ reaction. This high fraction of water molecules released into the gas phase from bare silicates upon formation is probably due to the low binding energy of the final products such as $\mathrm{OD}$ and $\mathrm{D}_{2} \mathrm{O}$ molecules (Cazaux et al. 2010).

Our experiments show that substrates and experimental conditions have a large influence on the final products (Chaabouni et al. 2012). However, previous results of Miyauchi et al. (2008) and Ioppolo et al. (2008) showed that water molecules are the major product of formation in the $\mathrm{O}_{2}+\mathrm{D}$ experiments, at least for the monolayer or the sub-monolayer regime.

In a future study we will compare surfaces and will investigate different substrates for the formation of water molecules.

\section{References}

Cazaux, S., Cobut, V., Marseille, M., Spaans, M., \& Caselli, P., 2010, A\&A, A74, 522

Chaabouni, H., Minissale, M., Manicò, G., et al., 2012, J. Chem. Phys., 137, 234706

Dulieu, F., Amiaud, L., Congiu, E., et al., 2010, A\&A, 512, A30

Ioppolo, S., Cuppen, H., et al., 2008, ApJ, 686, 1474

Jing, D., He, J., Brucato, J., et al., 2011, ApJ, 741, L9

Miyauchi, N., Hidaka, H., Chigai, T., et al., 2008, Chem. Phys. Lett., 456, 27

Mokrane, H., Chaabouni, H., Accolla, M., et al., 2009, ApJ, 705, L195

Tielens, A.G.G.M., \& Hagen, W., 1982, A\&A, 114, 245 